\title{
NOTES.
}

\section{ON THE INFLUENCE OF THE TEMPERATURE OF IIQUID HYDROGEN ON THE GERMINATIVE POWER OF}

SEEDS ${ }^{1}$. By Sir William T. Thiselton-Dyer, K.C.M.G., C.I.E., F.R.S.-The Comptes Rendus for August 28 (p. 434) contains a communication from Professor Dewar to M. Henri Moissan, 'relative à la solidification de l'hydrogène.' It concludes with the following sentence, which may be easily overlooked:- 'Des graines refroidies dans de l'hydrogène liquide conservent toute la propriété de germer.'

This is the first announcement of an interesting experiment in which Professor Dewar did me the honour to ask me to assist him. He has further suggested to me to put on record the facts, as far as they came under my observation, and any physiological conclusions to which they seem to point.

With this suggestion I have no alternative but to comply. Botanists will naturally expect some more detailed account than is contained in the brief announcement which I have quoted. But as my share in the research has been of the smallest, I should have much preferred that Professor Dewar should have given the result of the whole investigation himself.

When Professor Dewar first suggested the experiment to me, he pointed out that it would be a costly one, that it would only be possible to operate on very small quantities of seeds, and that the number of kinds must also be few.

1 From the Proceedings of the Royal Society, vol. lxv, I899.

[Annals of Botany, Vol. XIII. No. LII. December, 1899.] 
The dozen seeds experimented upon by Messrs. Brown and Escombe, which were submitted to the temperature of liquid air, were apparently selected as belonging to different natural families, and also in some degree as to their composition ${ }^{1}$. My choice was much more restricted. I took two out of their list for the sake of comparison : barley and vegetable marrow. I added wheat, which had more than once been made the subject of experiment. This gave me two farinaceous seeds and one oily one. I then took shape and bulk into account. Wheat and barley are roughly ellipsoidal and medium in size. The vegetable marrow is relatively large but flattened. I therefore added another oily seed, mustard, which is small and spherical. I followed Messrs. Brown and Escombe in taking a pea, which is also spherical in shape but nitrogenous in composition. Finally, I sought a very minute seed, and pitched upon musk.

The list then ultimately stood :-

\section{Brassica alba. \\ Pisum sativum. \\ Cucurbita Pepo. \\ Mimulus moschatus. \\ Triticum sativum. \\ Hordeum vulgare.}

The next point seemed to be to eliminate the source of error which might arise from defective germinative power. I therefore communicated the list to Messrs. Sutton \& Sons, of Reading, and asked their assistance. With their invariable kindness in any scientific inquiry, they willingly complied, and sent the samples required, with the following report:-

'We now have pleasure in sending a packet of each of the seeds you name. They are all of last year's growth, and of good germination.

' For your information we append the germinations arrived at by our tests made in March last of the various parcels from which these samples are taken.

- We have no doubt that each grain of wheat is a germinating seed, as specially fine seeds have been picked out.

'In the case of musk a good growth was obtained, but the germination was not counted.

\footnotetext{
1 Roy, Soc. Proc., vol. lxii, p. г6r.
} 
' Germinations :-

\begin{tabular}{|c|c|}
\hline Mustard . & roo per cent. \\
\hline "Bountiful" Peas. & 100 ", \\
\hline Vegetable marrow & $9^{6}$ \\
\hline Musk 。 . & Good. \\
\hline Wheat . & 96 \\
\hline Barley . & 100 \\
\hline
\end{tabular}

I forwarded the samples (which were small) to Professor Dewar, and suggested that they should be each divided into two portions, one for a control experiment under ordinary conditions, the other to be returned to me after being subjected to cooling. Owing to some misunderstanding, this was not done; but, as will be seen in the result, the omission proved immaterial. The seeds, it should be stated, were simply air-dried: they were ordinary commercial samples, and no attempt was made to further desiccate them.

I pointed out to Professor Dewar the advisability of exposing the seeds to extreme changes of temperature as gradually as possible, a precaution which Messrs. Brown and Escombe carefully observed ${ }^{1}$. He promised 'to consider what can be done to avoid any disaster from this cause.'

On July 2 I he wrote to me:- 'In spite of the weather I have carried out my promise, and cooled some seeds in liquid hydrogen for half an hour. I had to seal them up in a glass tube, cool first in liquid air, and then transfer to the hydrogen. They have, therefore, been cooled to $-250^{\circ} \mathrm{C}$., or $-25^{\circ} \mathrm{C}$., while being in a vacuum (seeing the air left had no appreciable tension). The seeds, in other words, have been transferred to a condition resembling that of moving through space. Another set of the seeds have been cooled only in liquid air for comparison.'

On July 22 he added, on returning the seeds:- 'There can be no doubt about the seeds being cooled, as they were in the hydrogen for more than an hour. In fact I used nearly 600 c.c. of liquid hydrogen.'

The seeds came to me in the small packets of tinfoil in which they had been placed in the tube. On opening these it was observed that the seeds were as fresh and bright as before being subjected to the treatment. There was not the slightest discoloration observable

\footnotetext{
1 Loc. cit., p. I6I.
} 
in the green tint of the peas. This practically disposed of the only anxiety which Professor Dewar felt as to the success of the experiment, and expressed to me on July 25 :-

'My own impression is that unless the sudden vacuum caused by the liquid hydrogen cooling has produced physical rupture of the seeds, they will germinate as usual. If they survive this awful strain, then I believe no increase of the time of cooling could produce any effect other than results from one hour's exposure to such severe cold.'

The seeds were sown in a cool greenhouse, without heat, on July 27 . On August I they had all germinated. In the case of the mustard, I 36 young plants were produced from 155 seeds; the remainder had, however, germinated, but the seedlings had damped off. One of the packets of wheat, for some reason, germinated slightly more slowly than the rest.

On August 5, I received a further packet of the seeds (the musk excepted) indiscriminately mixed. Professor Dewar wrote the same date:- 'I have sent you seeds to-day which, if the treatment with cold can kill, ought to be dead. They have been immersed in liquid hydrogen for upwards of six hours, and no attempt was made to graduate the cooling. They were placed in the vacuum vessel into which the liquid hydrogen could drop from the apparatus, and had to take their chance. The seeds have been soaked in liquid hydrogen, and in this respect differ from the last that were cooled in a vacuum from being sealed in a glass tube.'

In this instance again the seeds did not show the smallest visible trace of the ordeal to which they had been subjected. They were sorted out and immediately sown, under the same conditions as before. By August 9 the seeds had all germinated without exception. I communicated the result to Professor Dewar, and he informed me, August $15:-$ 'The temperature Fahrenheit to which the seeds were cooled was $-453^{\circ} \mathrm{F}$. below melting ice.'

These are the details of the experiment. As it is not likely to be often repeated, I have thought it worth while to place them on record as precisely as possible.

The first question that suggests itself, is what evidence we have for believing that the seeds have actually been brought to the almost inconceivable temperature with which they were surrounded. That they were so brought, Professor Dewar himself has not a shadow of 
doubt. That substances at widely extreme temperatures can remain in juxtaposition at least for some time, and still maintain them, is illustrated by a striking experiment shown by Professor Dewar at the Royal Institution on April $\mathbf{r}, \mathbf{I} 898$. Liquid air poured into a large silver basin heated to redness, remained apparently as quiescent at this high temperature as in cooler vessels, and maintaired a spheroidal condition. This is well understood. But the fact remains that liquid air with a temperature of about $-190^{\circ} \mathrm{C}$. was contained in a vessel which had a temperature of $800^{\circ} \mathrm{C}$, the difference in temperature between the two being $1000^{\circ} \mathrm{C}$.

If we turn for a moment to the effect of heat on living structure, we know that a temperature of $75^{\circ} \mathrm{C}$. is fatal to all protoplasm, because at that temperature its proteids are coagulated. Yet there is good evidence for the fact that seeds have been exposed for prolonged periods to a temperature above $100^{\circ} \mathrm{C}$, and yet have subsequently germinated. It may be taken as absolutely certain that in this case that temperature never reached the embryo, but must have been intercepted by the imperfect conducting power of the seed-coats. Cohn again has found that the spores of Bacillus subtilis survive prolonged boiling ${ }^{1}$, and a similar observation applies.

It is probable that plant structures are deficient in thermal transparency, and they are notoriously indifferent conductors. Nevertheless, it is difficult to believe that in the case of such small bodies as seeds, their being brought to the temperature with which they are surrounded can be more than a question of time.

That the thermal opacity of at least the seed-coats may be really considerable is not, however, impossible, even at low temperatures. The following remarks by Professor Dewar have an obvious bearing on this point :-

'Pictet, after an elaborate investigation, concluded that below a certain temperature all substances had practically the same thermal transparency, and that a non-conducting body became ineffective at low temperatures in shielding a vessel from the influx of heat. Experiments, however, prove that such is not the case, the transference of heat observed by Pictet appearing to be due not so much to the materials themselves as to the air contained in their interstices. Good exhaustion in the ordinary vacuum vessels used in low temperature work reduces the influx of heat to cne-fifth of what

${ }^{1}$ See Vines, Physiology of Plants, p. 283. 
is conveyed when the annular space of such double-walled vessels is filled with air ${ }^{1}$ '

It is to be noticed that in Professor Dewar's first experiment the seeds were practically in a vacuum. It is obvious, from what has been quoted above, that this would help them to retain their heat. Any hesitation in accepting the results of the experiment on this ground is, however, swept away by the second experiment, in which the seeds, with absolutely no protection at all, were actually soaked in liquid hydrogen for six hours. The extremity of caution can hardly resist the conclusion that they must have been brought to the same temperature.

Professor Dewar finds 'that silica, charcoal, lampblack, and oxide of bismuth all increase the insulation to four, five, and six times that of the empty vacuum space.' It might possibly be worth while to try how far a packing of small air-dry seeds would compare, say, with charcoal. And this would in some degree be a measure of the thermal transparency of seed structures.

Professor Dewar suggested to me that I should supplement this statement by some remarks on the physiological bearing of the experiment. This has already been discussed by Messrs. Brown and Escombe, and there is perhaps little of moment to add to their conclusions.

The real interest of the whole investigation obviously lies in the question how far it modifies our conceptions of the nature and properties of living matter. Protoplasm, whatever its source, has physical properties and an ultimate chemical composition which are practically uniform. This uniformity, however, overlies a potential diversity which is not to be measured. Such diversity cannot be accounted for by any purely physical conceptions, as physical conceptions are understood.

We not merely know the ultimate constitution of protoplasm, but we also know a good deal about its proximate constitution. Yet the properties of living protoplasm are very far removed from the mere sum of those of its constituents, and no light can be derived with respect to them in this direction. And what we know about the constituent bodies themselves is at present not a little obscure. They belong, as it were, almost to the fringe of possible chemistry, and almost elude the methods of chemical research. But they, complex as

${ }^{1}$ On Liquid Air as an Analytic Agent, Roy. Inst., Apr. I, I 898, pp. 7 and 8. 
they are, are not themselves protoplasm. Their cumbrous molecules are built up and broken down by ordinary chemical processes. They are not in themselves, in any intelligible sense, living, though essential to the exhibition of vital phenomena.

There our analysis of living matter by physical methods for the present stops. But we are justified in pushing, at any rate, semiphysical conceptions as far as we dare. We conceive, therefore, the physical constituent molecules of protoplasm as aggregated into larger molecules which, as they are unlike anything we know as purely physical, we call physiological ${ }^{1}$. Of the properties of such molecules we have some faint conceptions. The first is their instability. They are kinetic; 'living substance is continually breaking down into simpler bodies, with a setting free of energy; on the other hand living substance is continually building itself up, embodying energy into itself, and so replenishing its store of energy ${ }^{2}$ ' This kinetic condition is essentially life ; when it ceases, we have hitherto believed that the constituents of protoplasm come under the sway of purely inorganic conditions.

If we pause for a moment to attempt a quasi-mechanical explanation of the more developed phenomena of living organisms, such for example as are included under heredity, we are led to suppose that the physiological molecules may themselves be grouped into larger aggregates. And each stage of aggregation introduces us into a new order of phenomena. All that we can say is, that beyond the first stage the properties which are characteristic of higher molecular aggregrates are ultra-physical, taking physical in its ordinary signification. That does not imply, however, that physical conditions are ever in abeyance. Each stage of aggregation is conditioned by every one that precedes it. In this sense life rests au fond on a physical basis.

A continuous kinetic condition appears to be one distinctive property of physiological molecules. This not merely manifests itself in continuous chemical activity, but under appropriate conditions in actual visible motion. And it is to be remarked of the former, that though chemical in kind, it is undoubtedly ultra-chemical, as chemistry is understood in the laboratory. A further characteristic of the p. 6 .

' Identical with Foster's 'somacula,' Textbook of Physiology, Part I, fifth ed.,

${ }^{2}$ Foster, loc. cit., p. $4 \mathrm{I}$. 
physiological molecule is that it possesses the power of breaking up chemical combinations and reuniting their constituents in a way which absolutely eludes the methods available to the chemist, and entirely outstrides the pace at which he can preceed. There is the same kind of difference between the two methods as there is between arithmetic and the calculus in the solution of a mathematical problem.

The question then is, how far the effects of Professor Dewar's experiments, and of those who have preceded him in the same field, require us to modify our conception of the physiological molecule. Are we obliged to admit with Professor C. de Candolle and Messrs. Brown and Escombe that it may descend to a purely static condition?

This is really bound up with another question. The kinetic condition depends on the constant liberation of energy by chemical change. Of this the most important is that due to oxidation. But we now know that this is not the only source of energy in living matter, or in all cases the indispensable one. The late Dr. Romanes showed that neither a high vacuum nor subsequent exposure for twelve months to absolutely indifferent gases, such as hydrogen or nitrogen, or even poisonous ones, such as hydrogen sulphide, had any effect on the germinative power of seeds. Professor Pfeffer has, however, informed me in conversation that an injurious effect is ultimately produced.

Vital processes have their optimum point as regards temperature. Their superior limit, for the reason already pointed out, is tolerably sharp; but the inferior is by no means equally so. According to Boussingault the decomposition of carbon dioxide by green plants may take place nearly at $0^{\circ} \mathrm{C} .{ }^{1}$ Below the optimum there is then some evidence of a 'slowing down.' While some processes reach their limit, can we assume that all do?

The question would be peremptorily answered for us by those who assert that all chemical action is in abeyance at such temperatures as I am discussing. Photographic action still takes place at the temperature of liquid air, though this may be due to phosphorescence. But a jet of hydrogen will burn in it.

Messrs. Brown and Escombe sum up the two methods of explaining what has been called 'dormant vitality' with sufficient accuracy in their paper. According to the one view, metabolic and its resultant kinetic activity is 'slowed down' indefinitely. In such a case as now

\footnotetext{
1 Sachs, Textbook, second ed., p. 729.
} 
described, it might be said that this takes place along an asymptotic curve, continually approaching but never becoming equal to zero.

According to the other, protoplasm passes absolutely from the kinetic to the static condition. Its locked-up energy becomes purely potential, and Professor C. de Candolle has not hesitated under these circumstances to compare it to an explosive.

It has been pointed out that such a conclusion is absolutely in conflict with Mr. Herbert Spencer's well-known definition of life. But it appears to me that that definition was only intended to apply to higher stages of the aggregation of living matter than that of the physiological molecule on which I have endeavoured to fix the discussion. The question seems to me to be simply whether it is admissible to regard that as capable of being brought to an absolutely static condition.

Conceive two such molecules, one known to be living, but static, and the other dead, and both to be maintained in a condition in which they are not immediately susceptible to chemical change. What is the criterion of life? There is none. It seems to me then that the question I have propounded does not admit of any positive answer in the present state of our knowledge.

A problem, perhaps somewhat scholastic, which once vexed the souls of biologists was-whether life was the cause of organization or organization of life. What is to be our answer if our startingpoint is no more than a possible 'explosive'?

\section{ON THE STRUCTURE OF THE STEM OF A RIBBED} SIGILLARIA ${ }^{1}$. By Professor C. E. Bertrand.-The structure of certain species of Lepidodendron, e.g. L. selaginoides and L. Harcourtii, is well known, and we are in possession of some facts as to the anatomy of Sigillaria spinulosa and S. Menardi, species which belong to the section of the genus characterized by a smooth bark (Leiodermaria). On the other hand, we are still in want of data with regard to the structure of the Rhytidolepis section of Sigillariathe species with a ribbed bark. It has been suggested that some of the stems described under the name Diploxylon may very probably be partially decorticated Sigillarias.

In March of this year (1899) I received from the colliery of

1 Abstract (translated) of a paper read before the Botanical Section of the British Association, Dover, Sept. I 899 . 


\section{$2 \mathrm{BHL}$ Biodiversity Heritage Library}

Thiselton-Dyer, William T. 1899. "On the influence of the temperature of liquid hydrogen on the germinative power of seeds." Annals of botany 13, 599-607. https://doi.org/10.1093/oxfordjournals.aob.a088752.

View This Item Online: https://www.biodiversitylibrary.org/item/232524

DOI: https://doi.org/10.1093/oxfordjournals.aob.a088752

Permalink: https://www.biodiversitylibrary.org/partpdf/318558

\section{Holding Institution}

Smithsonian Libraries

\section{Sponsored by}

Biodiversity Heritage Library

\section{Copyright \& Reuse}

Copyright Status: Not in copyright. The BHL knows of no copyright restrictions on this item.

This document was created from content at the Biodiversity Heritage Library, the world's largest open access digital library for biodiversity literature and archives. Visit BHL at https://www.biodiversitylibrary.org. 